\title{
Biomechanical changes of degenerated adjacent segment and intact lumbar spine after lumbosacral topping-off surgery: a three-dimensional finite element analysis
}

\author{
Liangliang Cao' ${ }^{1}$ Yumei Liu², Wei Mei ${ }^{1^{*}}$, Jianguang $\mathrm{Xu}^{3^{*}}$ (1) and Shi Zhan ${ }^{3}$
}

\begin{abstract}
Background: Previous studies have revealed positive effect of Topping-off technique on upper adjacent segment after fusion surgery, while for the cases with fusion surgery on L5-S1 segment, owning maximal range of motion, and preexisting degenerated upper adjacent disc, it is necessary to clarify the superiority of Topping-ff technique and the effect exerted on the lumbar spine.

Methods: A young healthy male volunteer was selected for thin-slice CT scanning. Then the image information was imported into the computer to establish the whole lumbar spine model as the health model. The medium degeneration model of intervertebral disc was established by changing the material properties of L4-S1 disc on the basis of the health model, and the fusion model and Topping-off model were respectively established on the basis of the degenerated model. The variation trend of ROM of L2-L5 and the stress changes of L4-L5 intervertebral disc, nucleus pulposus and facet joints were calculated respectively.

Results: The L4-L5 ROM of fusion model increased significantly but the ROM of L2-L3 and L3-L4 segments did not change significantly. Compared with the degenerated model, L4-L5 activity of the Topping-off model decreased, and ROM of the L2-L3 and L3-L4 increased to some extent in the flexion and extension positions. The stress on the disc, nucleus pulposus and facet joint of the fusion model L4-L5 increased in four positions of flexion, extension, rotation and bending compared with the degenerated model, while the fiber stress on the Topping-off model decreased significantly in all four positions.

Conclusion: Topping-off technology can decrease the stress and ROM of the adjacent upper degenerated segment, and increase the ROM of other upper segments, thereby protecting the degenerated upper adjacent segments and compensating the lumbar spine mobility.
\end{abstract}

Keywords: Topping-off, Finite element, Biomechanics, Fusion

\section{Background}

In recent years, clinicians have paid more attention to the adjacent segment degeneration(ASDeg) being secondary to lumbar fusion. It is now generally accepted that increasing the fusion length promotes the occurrence of ASDeg [1-3]. In order to avoid the occurrence

\footnotetext{
*Correspondence: 13613711661@163.com; xjgn6spine@126.com 'Department of Spine Surgery, Zhengzhou Orthopaedics Hospital, 58 Longhai Middle Road, Zhengzhou City, Henan Province, China

${ }^{3}$ Department of Spine Surgery, Shanghai Jiao Tong University Affiliated Sixth People's Hospital, 600 Yishan Road, Xuhui District, Shanghai, China Full list of author information is available at the end of the article
}

of ASDeg, a variety of dynamic internal fixation systems are gradually used in clinical practice, including interspinous dynamic internal fixation system, transpedicular dynamic rod fixation, artificial disc replacement, etc [4]. Although interspinous dynamic internal fixation system, to some extent, can delay the emergence of ASDeg, fusion is often required in order to achieve fully decompression and stability for patients with severe spinal stenosis or lumbar instability $[5,6]$. The topping-off technique, combining lumbar fusion with the dynamic interspinous internal fixation system (Coflex), can not

(c) The Author(s). 2020 Open Access This article is distributed under the terms of the Creative Commons Attribution 4.0 International License (http://creativecommons.org/licenses/by/4.0/), which permits unrestricted use, distribution, and reproduction in any medium, provided you give appropriate credit to the original author(s) and the source, provide a link to the Creative Commons license, and indicate if changes were made. The Creative Commons Public Domain Dedication waiver (http://creativecommons.org/publicdomain/zero/1.0/) applies to the data made available in this article, unless otherwise stated. 
only provide adequate decompression to achieve good clinical efficacy but also protecting preexisting degenerated adjacent segments [7].

Several previous studies have revealed biomechanical characteristics after fusion on L3-L5 [8-10] based on healthy disc model, while fusion on L5-S1 also frequently in clinics, and considering of about $30 \%$ of the lumbar spine's mobility existing on L5-S1, it is necessary to protect preexisting degenerated L4-L5 segment,especially for young patients. Based on the lumbar disc degeneration model, Topping-off model can provide a more accurate manifestation to the biomechanical effects on adjacent segments and entire lumbar. In addition, the supraspinal ligament was preserved and semi-laminar decompression was simulated in Topping-off model to realize highly accordance with the actual operation, and Coflex was selected as the interspinous process device.

\section{Methods}

\section{Health model(HM)}

Computed tomography scans of intact lumbar spine at 1 -mm intervals were obtained from a healthy 25-yearsold male volunteer, who was randomly selected and signed the informed consent. The FE program, ANSYS Inc. (Canonsburg, PA, USA), was used to model the spinal segments. Ligaments including ligamenta supraspinal, ligamenta interspinalia, capsular ligament, ligamentum flavum, ligamenta longitudinale posterius, ligamenta longitudinale anterius and ligamenta intertransversaria, and intervertebral disc were reconstructed according to anatomy data. The intervertebral disc and nucleus pulposus were meshed directly based on their facial meshes. The cortex was inwardly expanded by $1 \mathrm{~mm}$, and then the inner side of the cortex was identified by Findface function to mesh the cancellous bone by the tetramesh function. The interface of Zygapophyseal joint was set as surface-to-surface contact with a friction coefficient of 0.1 . The disc was consisted of nucleus pulposus, fibrous ring matrix and annulus fibrosus. The nucleus pulposus accounted for about $50 \%$ of the disc area and the thickness was set to $1 \mathrm{~cm}$. Then the nucleus pulposus and fibrous ring matrix were both set as hyperelastic material, and the nucleus pulposus was incompressible liquid unit, while the annulus fibrosus was composed of fibrous ring matrix and collagen fiber which was simulated by two-node link elements with resistance tension only, and embedded in the fiber ring matrix with 8 layers and angles of positive-negative $30^{\circ}$ to the end plate. The end plate with the thickness of $1 \mathrm{~mm}$ covered the upper and lower surface of the vertebrae. Meanwhile, the posterior facet space was set to $0.5 \mathrm{~mm}$. Finally, the model was simulated according to the parameters reported in the current literature, and the specific data is shown in Table $1[8,9,11-13]$.
Table 1 Material properties of the finite element model

\begin{tabular}{lll}
\hline Anatomic structure & $\begin{array}{l}\text { Modulus of } \\
\text { elasticity(MPa) }\end{array}$ & $\begin{array}{l}\text { Poisson's } \\
\text { ratio }\end{array}$ \\
\hline Osseous cortex [10] & 12,000 & 0.3 \\
Cancellous bone [10] & 100 & 0.2 \\
End plate [11] & 24 & 0.4 \\
Nucleus pulposus [10] & 1666.7 & - \\
Fiber ring matrix [8] & 4.2 & 0.45 \\
Annulus fibrosus [10] & 500 & 0.3 \\
Ligamenta longitudinale & 20 & 0.3 \\
anteriust [9] & & \\
Ligamenta longitudinale & 70 & 0.3 \\
posterius [9] & & \\
Ligamentum flavum [9-13] & 50 & 0.3 \\
Ligamenta interspinalia [9-13] & 28 & 0.3 \\
Ligamenta supraspinale [9-13] & 28 & 0.3 \\
Articular capsule ligament [9-13] & 20 & 0.3 \\
ligamenta intertransversaria & 50 & 0.3 \\
[9-13] & &
\end{tabular}

\section{Degenerated model(DM)}

Based on the healthy group model, we constructed moderate degenerated model by changing properties of annulus fibrosus and nucleus pulposus in L4-L5and L5S1 segment [12]. Specifically, the material of nucleus pulposus was changed into a solid unit as well as the modulus of elasticity was set to $833.4 \mathrm{Mpa}$, and the elastic modulus of the fiber ring matrix was set to 8.4 Mpa.

\section{Fusion model(FM)}

The geometric figure of pedicle screws, rods and cage were developed in Rhinoceros 5.0 (Robert McNeil \& Associates, USA) according to their parameters, and meshed with hypermesh (Fig. 1). Then these surgical instruments were assembled with the degenerated model as standard surgery, and the L5-S4 segment of the healthy model underwent partial discectomy and total nuclectomy by the posterior approach, which included removal of the semi-laminar, ipsilateral inferior articular process, posterior portions of the annulus and the entire nucleus pulposus. The elastic modulus and Poisson's ratio of screw-rod system and cage were set as 120,000 $\mathrm{MPa}$ and $3600 \mathrm{MPa}$, and 1.33 and 0.38 respectively. The interfaces of screw-rod, screw-vertebra, and cageendplate were designed to be fully constrained.

\section{Topping-off model(TM)}

The appropriate Coflex model with the same material properties with the screw-rod system was inserted into L4-5 interspinous space of fusion model, as shown in Fig. 2. Different from the fusion model, the interspinous ligament of L4-L5 level was removed but the 


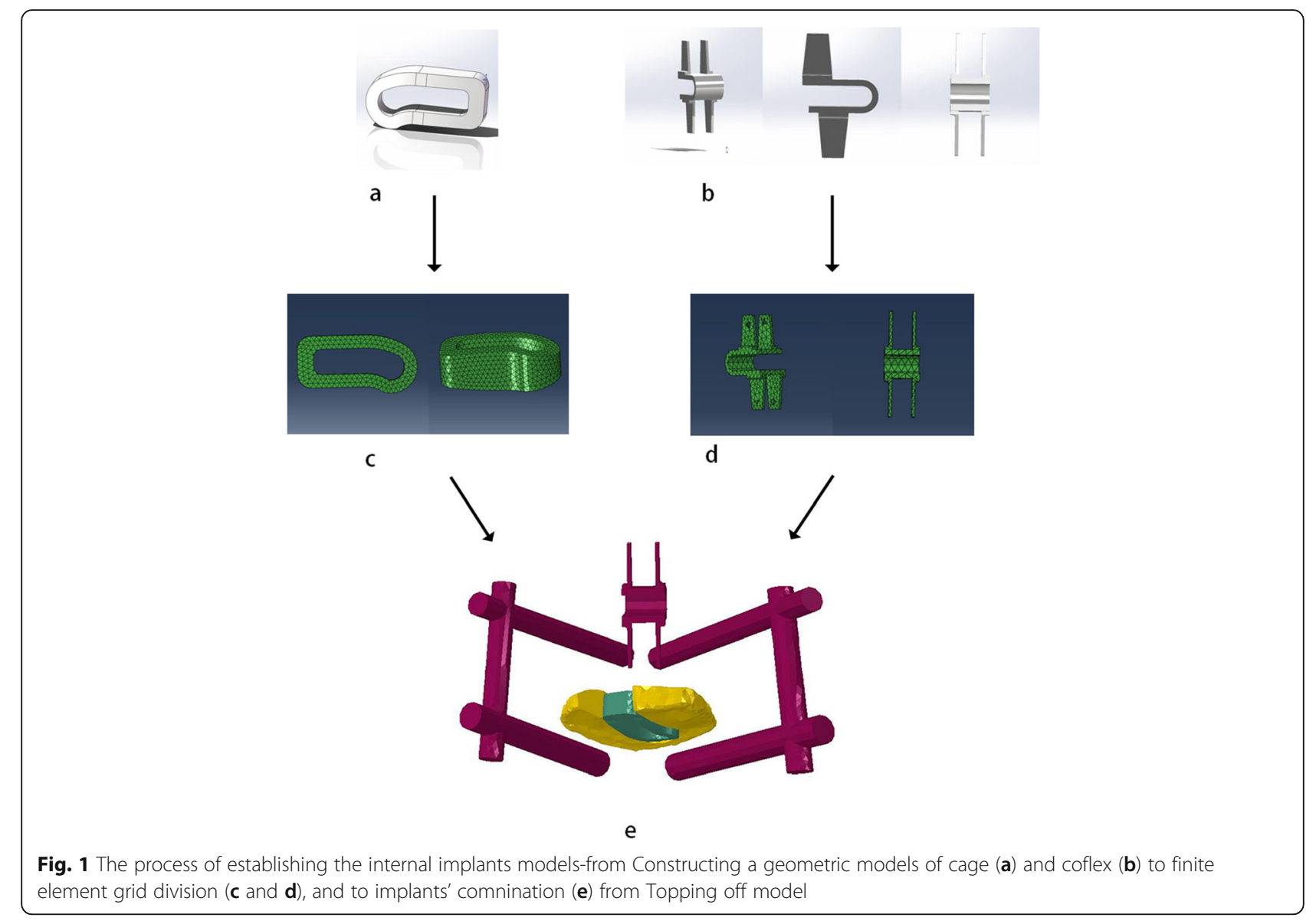

supraspinous ligament was preserved. The contact of two wings of Coflex with spinous process was set as binding contact, and the dentate part was ignored.

\section{Loading conditions}

The fixed boundary condition restrained the inferior surface of the S1 segment in these models. A compressive load of $400 \mathrm{~N}$ and $10 \mathrm{Nm}$ of momentum, rather than displacement on the most upper part of the spine models to simulate physiological activity, were applied on the superior surface of the L1 to generate compression, flexion, extension, rotation and lateral bending. In this study, range of motion (ROM) of each segment, intradiscal pressures and facet joints contact force of L4/L5 segment were examined in those 4 motions generated. Stress collection was mainly done by collecting the stress values of every node on the disc and nucleus pulposus of each segment in various positions and then calculating

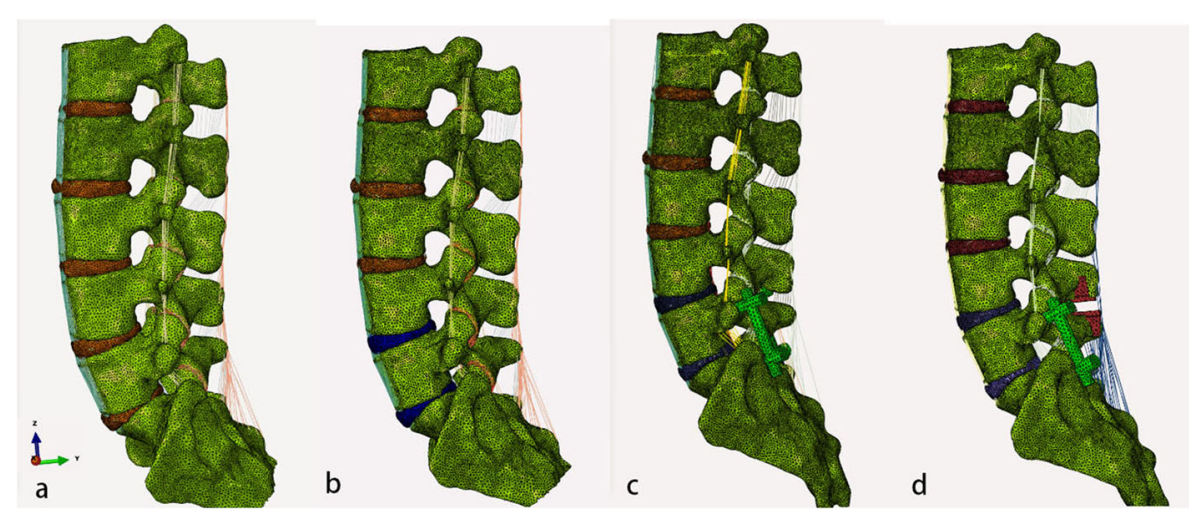

Fig. $\mathbf{2}$ Lateral aspects of the health model (a), degenerated model (b), fusion model (c) and Topping-off model (d) 
the average values. The variation of ROM was evaluated by the angular displacement. That is to say, the angle variation of superior surface line was confirmed according to the coordinate changes of the two nodes on the endplate of midsagittal view in states with $400 \mathrm{~N}$ compressive load and compressive load of $400 \mathrm{~N}+10 \mathrm{Nm}$ of momentum respectively. Each ROM was calculated three times, and finally the average value was collected. The formula is as follows:

$$
\mathrm{ROM}=\left|\frac{180}{\pi} \times \arctan \frac{\mathrm{y} 2-\mathrm{y} 1}{\mathrm{x} 2-\mathrm{x} 1}-\frac{180}{\pi} \times \arctan \frac{\mathrm{y} 2 \cdot-\mathrm{y} 1^{\circ}}{\mathrm{x} 2 \cdot-\mathrm{x} 1}\right|
$$

\section{Results}

These models were validated before analysis of the result (Table 2). The stiffness result measured from the healthy model was compared with earlier biomechanical results from cadavers [14-17] and showed similar results. The difference between this study and Yamamoto's study was not significantly. The difference is considered to occur due to the difference from the models details and selected subjects.

Compared with the healthy model, the ROM of the total lumbar spine of the rest three models all decreased in the postures of anterior flexion, posterior extension, left bending, and left rotation. [see Additional file 1] The ROM of L4-L5 segment of Topping-off model decreased significantly by $28.39 \%, 62.43 \% 、 30.82$ and $36.45 \%$ in flexion, extension, axial rotation and lateral bending, while that of the fusion model increased by 38.31 and $21.70 \%$ in flexion and extension, when compared with degenerated model. L3-L4 segment and L2/L3 segment in Topping-off model respectively resulted in increase by $24.77 \%$ in flexion and 20.21, 130.23 , and $32.45 \%$ in flexion, extension and axial rotation, while fusion model did not affect ROM of other segments compared with that of the degenerated model. Compared with degenerated model, the stress of annulus fibrosus, nucleus pulposus and articular process of fusion model all increased obviously in each active position, specially for flexion and extension, and the stress of the three elements in
Topping-off model decreased significantly in anteflexion and extension position (Fig. 3).

\section{Discussion}

The non-fusion surgery can minimize the influence on adjacent segments by preserving the motion of the lesion segments to prevent the occurrence of ASDeg. However, when faced with severe clinical situation of lumbar instability, osteoporosis and severe spinal stenosis, fusion is usually needed $[5,6,13,18]$. The increase of movement and stress of adjacent segments after fusion is the main cause of ASDeg, moreover, for the degenerated adjacent disc, fusion may accelerate degeneration process, even result in symptomatic degeneration $[19,20]$, especially for those with indications of fusion and moderate degeneration in the superior adjacent disc(Pfirrmann grade II-IV) [21], the fusion segments should be minimized while achieving good clinical results. As a hybrid internal fixation technique, Topping-off technique may be a fair way to solve the situation [10, 22, 23].

Limited to the fact that the internal mechanical environment of the human body cannot be measured directly, the three-dimensional finite element analysis method is used to simulate the internal mechanical environment of the human body through the establishment of effective lumbar spine models. The biomechanical analysis of the entire lumbar after Topping-off were performed in the lumbosacral junction region where the biomechanical environment of lumbosacral region changed into a rigid lever consisted of pelvis, sacrum and L1-L5 segments together after L5-S1 fusion and then the stress and mobility of upper segments increased due to the relative stability of the pelvis and sacrum. There are a few studies on the changes of mechanical environment after Topping-off technique at present, nevertheless, the changes of mechanical environment of lumbosacral junction region with relatively concentrated stress and the influence of topping-off on the whole lumbar mechanical environment have rarely been referred. In addition, This study showed that, compared with the healthy model, the stress of annulus fibrosus and nucleus pulposus of L4-L5 in degenerated model increased

Table 2 Stiffness comparison with the results of the list literature

\begin{tabular}{llllll}
\hline & $\begin{array}{l}\text { Moment } \\
(\mathrm{Nm})\end{array}$ & $\begin{array}{l}\text { Anteflexion } \\
\left(\mathrm{N} \cdot \mathrm{m} /{ }^{\circ}\right)\end{array}$ & $\begin{array}{l}\text { Postextension } \\
\left(\mathrm{N} \cdot \mathrm{m} /{ }^{\circ}\right)\end{array}$ & $\begin{array}{l}\text { Left rotation } \\
\left(\mathrm{N} \cdot \mathrm{m} /{ }^{\circ}\right)\end{array}$ & $\begin{array}{l}\text { Left bending } \\
\left(\mathrm{N} \cdot \mathrm{m} /{ }^{\circ}\right)\end{array}$ \\
\hline Heth et al. [14] & 10 & 1.1 & 2.35 & 1.33 & 2.61 \\
Li et al. [15] & 6 & 1.62 & 3.03 & 2.5 & 4.45 \\
Liu et al. [16] & 10 & 2.35 & 3.58 & 2.86 & 8.98 \\
Yamamoto et al. [17] & 10 & 1.75 & 3.22 & 2.44 & 5.66 \\
This study & 10 & 1.69 & 2.7 & 1.58 & 4.02 \\
$P$ value & $/$ & 0.957 & 0.274 & 0.296 & 0.372 \\
\hline
\end{tabular}

The $p$ values were determined with the one-simples T test 


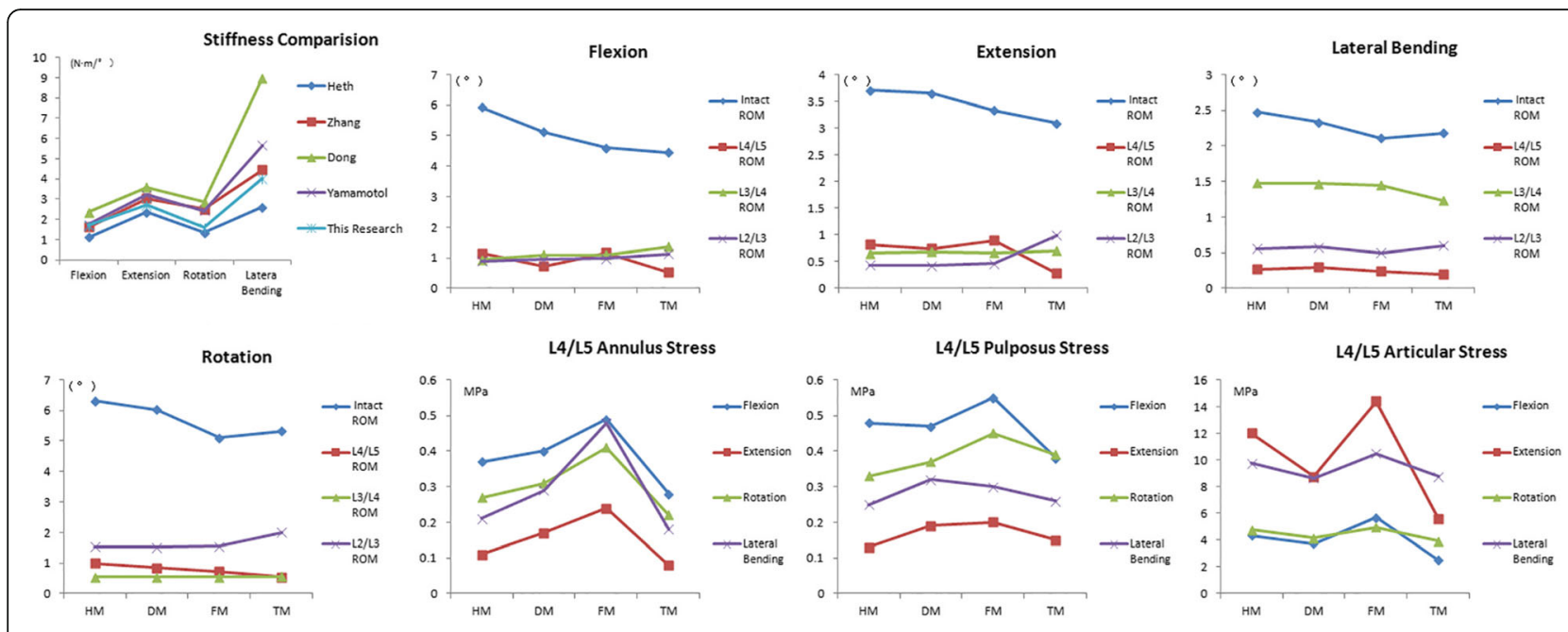

Fig. 3 Stiffness conmparision results and ROM and von Mises stress distribution changes among various surgical models under flexion, extension, lateral bending, and axial rotation

in flexion, extension, axial rotation and bending position, while the ROM of each segment and the stress of posterior joints decreased. So, early disc degeneration may result in a change in the biomechanical state of the corresponding segments. Therefore, in order to study the effects of lumbar fusion and Topping-off on the superior segments, it was rational that the fusion model and Topping-off model were created based on the degenerated model, and then compared with the degenerated model. Previous studies have shown that the degeneration of discs mainly lies in the decrease of proteoglycan concentration and collagen fibrosis, resulting in an increase in the hardness of discs [24, 25]. So, the establishment of the moderate degenerated model was mainly achieved by increasing the elastic modulus of the annulus fibrosus, reducing the volume of the elastic matrix of the annulus fibrosus and reducing the elastic modulus of the nucleus pulposus.

Those results showed an significant increase in ROM of L4-L5 in the fusion model under different positions, especially in flexion, but no significant changes were observed in other segments. Therefore, the compensatory effect of lumbar motion after fusion mainly focused on the L4-L5 segment. Excessive activity results in the change of rotation center in the corresponding segment, which may not only tend to impair the annular fiber and endplate and lead to poor blood supplying, lower nutrition diffusivity and hydraulic permeability, but also influence the resulting forces in the facet joints, making for the resultant apoptosis and accelerated degeneration [26-29]. Several studies have shown that mechanical stimulation plays an important role in the regulation of disc biology and this has indicated that mechanical overloading is a risk factor for disc degeneration [30, 31]. As revealed in the results, Topping-off surgery significantly reduced the mobility of L4-L5 in the flexion and, to some extent, increased the ROM of L2-L4 segments, especially in flexion and extension position. Considering of the slight decrease in ROM of intact lumbar, it indicated that Coflex could not only limit the hyperactivity of the adjacent segments, but also distribute the compensatory effect of lumbar spine motion to the upper segments after fusion. And the intradiscal pressure was largest in the anteflexion position, which explained that thoracic disc frequently occurs in the anteflexion position in the clinic [32], and indirectly proved the validity of models.

In the lumbosacral junction region where the stress is relatively concentrated, increased disc and facet joints stress of the superior adjacent segment after L5-S1 fusion may lead to changes of biomechanical environment and structural disorders of disc, and make the intervertebral space narrow gradually, especially for the disc that has already degenerated [33]. Facet joints and disc are involved in maintaining stability and in the coupling movement of the spine in different directions. Hyperactivity may result in chronic pressure overload of disc and facet joints. Compared with degenerated model, pressure overload may result in pressure concentration, and then joints wear and remolding [34, 35]. Eventually, under the sustained influence of hyperactivity and pressure overload, moderate degenerated discs gradually develop into the degeneration of the whole segment. In this study, decreased ROM and stress of upper adjacent level indicated that Topping-off could protect facet joints and degenerated disc from hyperactivity and excessive stress,the hyperactivity of adjacent segments, but also reduce the stress of discs and facet joints and delay the progress of degenerated disc by compensating the 
lost motion of lumbar spine through other adjacent segments over time. In addition, in order to prevent the occurrence of ASDeg, clinicians should improve the surgical skills as much as possible, cause less damage to the superior articular capsule [36], and restore the lumbar kyphosis as far as possible [37].

\section{Conclusion}

The results of the present models predict the effect of Topping-off surgery on the reduction of disc and facet joints stress and hyperactivity of the upper adjacent segment, and the ability of distributing the compensatory effect of lumbar spine motion to the upper segments after fusion. Thus it may protected the upper adjacent degenerated disc from progress to symptomatic degeneration. This study has some deficiencies which should combine with cadaveric experiments and incorporate simulation of paravertebral muscles, the role of which in maintaining stability of the spine can not be neglect, in the future studies.

\section{Supplementary information}

Supplementary information accompanies this paper at https://doi.org/10. 1186/s12891-020-3128-5.

Additional file 1. Stress and displacement of four models under different physiological loads.

\section{Abbreviations}

ASDeg: Adjacent segment degeneration; DM: Degenerated Model; FM: Fusion Model; HM: Health Model; ROM: Range of motion; TM: Toppingoff; Model

\section{Acknowledgements}

Not applicable.

\section{Authors' contributions}

LLC and YML were the major contributors in writing the manuscript. LLC and SZ performed the models' establishment and the data collection. LLC performed the statistical analysis. The collected data was discussed with JGX and WM. JGX and WM supported the structuring of the manuscript and helped to finalise the manuscript. All authors read and approved the final manuscript.

\section{Funding}

No funding was obtained for this study.

\section{Availability of data and materials}

Some availability of data and materials were uploaded,and and corresponding author J Xu can be contacted to request the raw data.

\section{Ethics approval and consent to participate}

The study was approved by Ethics Committee of Shanghai Sixth People's Hospital. Written informed consent was available, and participant involved gave his consent for the use of individual data and experimental data.

\section{Consent for publication}

Not Applicable.

\section{Competing interests}

All other authors declare that they have no competing interests.

\section{Author details}

'Department of Spine Surgery, Zhengzhou Orthopaedics Hospital, 58 Longhai Middle Road, Zhengzhou City, Henan Province, China. ${ }^{2}$ Fudan University Shanghai Cancer Center, 270 Dong'an Road, Xuhui District, Shanghai, China. ${ }^{3}$ Department of Spine Surgery, Shanghai Jiao Tong University Affiliated Sixth People's Hospital, 600 Yishan Road, Xuhui District, Shanghai, China.

Received: 22 August 2019 Accepted: 10 February 2020

Published online: 15 February 2020

\section{References}

1. Etebar S, Cahill DW. Risk factors for adjacent-segment failure following lumbar fixation with rigid instrumentation for degenerative instability. J Neurosurg. 1999;90(2 Suppl):163-9.

2. Yang JY, Lee JK, Song HS. The impact of adjacent segment degeneration on the clinical outcome after lumbar spinal fusion. Spine. 2008;33(5):503-7.

3. Mannion AF. ISSLS prize winner: long-term follow-up suggests spinal fusion is associated with increased adjacent segment disc degeneration but without influence on clinical outcome: results of a combined follow-up from 4 randomized controlled trials. Spine. 2014;39(17):1373-83.

4. Lee YC, Zotti MGT, Osti OL. Operative management of lumbar degenerative disc disease. Asian Spine J. 2016;10(4):801

5. Gala RJ, Russo GS, Whang PG. Interspinous implants to treat spinal stenosis. Curr Rev Musculoskelet Med. 2017;10(2):182-8

6. Landi A. Interspinous posterior devices: what is the real surgical indication? World J Clin Cases. 2014;2(9):402-8

7. Chen $\mathrm{XL}$, et al. Interspinous dynamic stabilization adjacent to fusion versus double-segment fusion for treatment of lumbar degenerative disease with a minimum follow-up of three years. Int Orthop. 2016;40(6):1275-83.

8. Faizan A. Biomechanical rationale of ossification of the secondary ossification center on apophyseal bony ring fracture: a biomechanical study. Clin Biomech (Bristol, Avon). 2007:22(10):1063-7.

9. Sylvestre PL, Villemure I, Aubin CE. Finite element modeling of the growth plate in a detailed spine model. Med Biol Eng Comput. 2007:45(10):977-88.

10. Zhu Z, Liu C, Wang K. Topping-off technique prevents aggravation of degeneration of adjacent segment fusion revealed by retrospective and finite element biomechanical analysis. J Orthop Surg Res. 2015;10:10.

11. Polikeit A, Nolte L, Ferguson SJ. The effect of cement augmentation on the load transfer in an osteoporotic functional spinal unit: finite-element analysis. Spine. 2003;28(10):991-6.

12. Kumaresan S, Yoganandan N, Pintar FA, Maiman DJ, Goel VK. Contribution of disc degeneration to osteophyte formation in the cervical spine a biomechanical investigation. J Orthop Res. 2001;19(5):977-84.

13. Byun DH, Shin DA, Kim JM, Kim SH, Kim HI. Finite element analysis of the biomechanical effect of coflex $^{\mathrm{TM}}$ on the lumbar spine. Korean J Spine. 2012; 9(3):131-6.

14. Heth JA, Hitchon P, Goel VK, Rogge TN, Drake JS, Torner JC. A biomechanical comparison between anterior and transverse interbody fusion cages. Spine. 2001;26(12):E261-7.

15. Li D, Hai Y, Meng X. Topping-off surgery vs posterior lumbar interbody fusion for degenerative lumbar disease: a comparative study of clinical efficacy and adjacent segment degeneration. J Orthop Surg Res. 2019; 14(1):197.

16. Liu C, Kamara A, Yan Y. Investigation into the biomechanics of lumbar spine micro-dynamic pedicle screw. BMC Musculoskelet Disord. 2018;19(1):231.

17. Yamamoto I, Panjabi M, Crisco T, Oxland T. Three-dimensional movements of the whole lumbar spine and lumbosacral joint. Spine. 1989:14(11):1256-60.

18. Sobottke $R$, et al. Interspinous implants (X stop, Wallis, Diam) for the treatment of LSS: is there a correlation between radiological parameters and clinical outcome? Eur Spine J. 2009;18(10):1494-503.

19. Liang J, Dong Y, Zhao H. Risk factors for predicting symptomatic adjacent segment degeneration requiring surgery in patients after posterior lumbar fusion. J Orthop Surg Res. 2014;9:97.

20. Herren C, Sobottke R, Pishnamaz M, Scheyerer MJ, Bredow J, Westermann L, Berger EM, Oikonomidis S, Eysel P, Siewe J. The use of the DTO hybrid dynamic device: a clinical outcome- and radiological-based prospective clinical trial. BMC Musculoskelet Disord. 2018;19(1):199.

21. Pfirrmann $\mathrm{CW}$, et al. Magnetic resonance classification of lumbar intervertebral disc degeneration. Spine. 2001;26(17):1873-8. 
22. Choi J, Kim S, Shin DA. Biomechanical comparison of spinal fusion methods using Interspinous process compressor and pedicle screw fixation system based on finite element method. J Korean Neurosurg Soc. 2016;59(2):91-7.

23. Liu HY, Zhou J, Wang B, Wang HM, Jin ZH, Zhu ZQ, Miao KN. Comparison of Topping-off and posterior lumbar interbody fusion surgery in lumbar degenerative disease: a retrospective study. Chin Med J. 2012;125(22):3942-6.

24. Murakami H, Yoon TS, Attallah-Wasif ES, Kraiwattanapong C, Kikkawa I, Hutton WC. Quantitative differences in intervertebral disc-matrix composition with age-related degeneration. Med Biol Eng Comput. 2010; 48(5):469-74.

25. Hirsch C. Studies on the pathology of low back pain. J Bone Joint Surg (Br). 1959;:41-B(2):237-43.

26. Johannessen W, Elliott DM. Effects of degeneration on the biphasic material properties of human nucleus pulposus in confined compression. Spine (Phila Pa 1976). 2005;30(24):E724-9.

27. Gu WY, et al. Diffusivity of ions in agarose gels and intervertebral disc: effect of porosity. Ann Biomed Eng. 2004;32(12):1710-7.

28. Gu W, et al. Simulation of the progression of intervertebral disc degeneration due to decreased nutritional supply. Spine (Phila Pa 1976). 2014;39(24):E1411-7.

29. Schmidt $\mathrm{H}$, et al. The relation between the instantaneous center of rotation and facet joint forces - A finite element analysis. Clin Biomech (Bristol, Avon). 2008;23(3):270-8.

30. Yan Z, et al. Static compression induces ECM remodeling and integrin alpha2beta1 expression and signaling in a rat tail caudal intervertebral disc degeneration model. Spine (Phila Pa 1976). 2017;42(8):E448-58.

31. Chan SCW, Ferguson SJ, Gantenbein-Ritter B. The effects of dynamic loading on the intervertebral disc. Eur Spine J. 2011;20(11):1796-812.

32. Bergknut $\mathrm{N}$, et al. Intervertebral disc degeneration in the dog. Part 1: anatomy and physiology of the intervertebral disc and characteristics of intervertebral disc degeneration. Vet J. 2013;195(3):282-91.

33. Masharawi Y, Rothschild B, Dar G, Peleg S, Robinson D, Been E, Hershkovitz I. Facet orientation in the thoracolumbar spine: three-dimensional anatomic and biomechanical analysis. Spine. 2004;29(15):1755-63.

34. Kozanek M, et al. Range of motion and orientation of the lumbar facet joints in vivo. Spine. 2009;34(19):689-96.

35. Jones-Quaidoo SM, Djurasovic M, Owens RK 2nd, Carreon LY. Superior articulating facet violation: percutaneous versus open techniques. J Neurosurg Spine. 2013;18(6):593-7.

36. Umehara S, Zindrick MR, Patwardhan AG, Havey RM, Vrbos LA, Knight GW, Miyano S, Kirincic M, Kaneda K, Lorenz MA. The biomechanical effect of postoperative hypolordosis in instrumented lumbar fusion on instrumented and adjacent spinal segments. Spine. 2000;25(13):1617-24.

37. Schlegel JD, Smith JA, Schleusener RL. Lumbar motion segment pathology adjacent to thoracolumbar, lumbar, and lumbosacral fusions. Spine. 1996; 21(8):970-81.

\section{Publisher's Note}

Springer Nature remains neutral with regard to jurisdictional claims in published maps and institutional affiliations.

Ready to submit your research? Choose BMC and benefit from:

- fast, convenient online submission

- thorough peer review by experienced researchers in your field

- rapid publication on acceptance

- support for research data, including large and complex data types

- gold Open Access which fosters wider collaboration and increased citations

- maximum visibility for your research: over $100 \mathrm{M}$ website views per year

At BMC, research is always in progress.

Learn more biomedcentral.com/submissions 